\title{
PNE 2014-2024: TECNOLOGIAS EDUCACIONAIS E FORMAÇÃO DE PROFESSORES
}

\author{
Dilmeire Vosgerau \\ Glaucia da Silva Brito \\ Nuria Camas
}

\begin{abstract}
RESUMO: A partir da compreensão dos desafios vivenciados na educação em tempos de cibercultura e, principalmente, no que tange à inserção da cultura digital no ambiente escolar, neste artigo traçamos como objetivo analisar, no texto do Plano Nacional de Educação 2014-2024, o que foi mantido e aprovado sobre formação de professores e tecnologias educacionais. O processo de análise de dados ocorreu a partir da técnica de codificação aberta, que, na sequência, foi categorizada e validada pelos três pesquisadores e submetida à discussão a partir do referencial sobre formação de professores em uma era de cultura digital. Os resultados demonstram que a relação das tecnologias com a formação de professores está presente na meta 1, que trata da educação infantil, na meta 3, que aborda o ensino médio, e na meta 10, que se refere à educação profissional. Também se destaca na análise a produção de tecnologia, sem, no entanto, haver uma indicação precisa da participação do professor nessa produção. Conclui-se que houve um avanço em relação a documentos anteriores na preocupação com as tecnologias educacionais, mas ainda há muito a ser feito nos planos estaduais e municipais para que a formação do professor de fato ocorra e para que ele não seja um mero utilizador de tecnologias para ensinar e, sim, um mediador do processo de construção da aprendizagem, que utiliza a tecnologia como um catalisador.
\end{abstract}

PALAVRAS-CHAVE: PNE. Formação de professores. Tecnologias educacionais. Cultura digital

\begin{abstract}
Due to the comprehension of challenges met in education in cyber cultural times, and mainly about the challenges on the introduction of digital culture in the school environment, this text intends to do an analysis through the 2014-2024 Educational National Plan, which relates to teacher's formation and educational technologies, was kept and approved. Data analysis process was done by open codification, which was categorized and validated by three researchers and submitted to discussion from a point of view of teacher's formation in a digital culture era. Results showed that the relation to technologies with teacher's formation is present in target 1, which relates to children's education, in target 3 , which relates to High School, and in target 10, which relates to professional education. The production of technology is also highlighted, without having a precise participation of the teacher in this process. The conclusion was that there was an advancement in relation to previous documents which related to educational technologies, but there is still a lot to be done on city and state levels concerning teacher's formation, and also with the intent of making the teacher more than a mere user of the technology in teaching, but mainly as a mediator in the process of learning construction, which uses technology as a catalyst.
\end{abstract}

KEYWORDS: Teacher's formation. Educational technologies. Digital culture. 


\section{autêntica}

\section{INTRODUÇÃO}

Por entendermos que novos desafios são sentidos e vivenciados na educação em tempos de cibercultura e, principalmente, no que tange à inserção da cultura digital no ambiente escolar por meio da presença e adoção da internet e outros recursos digitais nesse ambiente, neste artigo traçamos como objetivo analisar, no texto do Plano Nacional de Educação (PNE) 2014-2024, o que foi mantido e aprovado sobre formação de professores e tecnologias educacionais.

Partimos do entendimento de que cultura digital é o resultado de um conjunto de ações que utilizam a mediação das Tecnologias da Informação e Comunicação (TICs) como marca social do nosso tempo (CASTELLS, 1999; LÈVY, 1996, 1999). Trata-se de uma revolução digital em que "a informação representa o principal ingrediente de nossa organização social, e os fluxos de mensagens e imagens entre as redes constituem o encadeamento básico de nossa estrutura social" (CASTELLS, 1999, p. 55).

As redes de computadores expandiram-se de tal forma que as tecnologias digitais consolidam-se cada vez mais como infraestrutura do ciberespaço - novo espaço de comunicação, sociabilidade, informação e conhecimento (LÈVY, 1999). Nessa cultura, o computador, o notebook, o celular e o tablet não se limitam à mera condição de instrumento de trabalho, mas tornam-se aparelhos que proporcionam

a realização de encontros sociais e particulares, processamento e transmissão de dados, a elaboração de atividades de trabalho e de diversão, televisão e comunicação, concentração e dispersão, ser ignorado ou ser percebido, a ponto de todas essas potencialidades se tornarem indiscerníveis entre si (TÜRCKE, 2010, p. 44).

Barreto (2012, p. 1) alerta sobre os desafios que temos de enfrentar na educação brasileira, ao refletir que "mais pode ser igual a menos", levando-nos a pensar nas formações aligeiradas como preenchimento do vazio que se vive. A grande questão que devemos ter respondida é a realização de formações em escalas monstruosas que vivenciamos, para dizer que estamos pensando na formação do professor, apesar de não termos a mínima noção do que ele precisa em sua escola para inserir-se na cultura digital, tampouco do que ele tem se apropriado na sua vivência na cultura digital. A expansão que reduz aprofunda as desigualdades.

O processo de integração das tecnologias digitais na ação pedagógica deveria corresponder à existência de modelos pedagógicos e de currículos que dessem significado educativo ao uso das tecnologias educacionais em sala de aula e para além dela.

\section{TECNOLOGIAS NA EDUCAÇÃO E FORMAÇÃO DE PROFESSORES}

O termo "tecnologia" vai muito além da mera relação com equipamentos, como conceitua Bueno (1999, p. 87):

Tecnologia é um processo contínuo através do qual a humanidade molda, modifica e gera a sua qualidade de vida. Há uma constante necessidade do ser humano de criar, a sua capacidade de interagir com a natureza, produzindo instrumentos desde os mais primitivos até os mais modernos, utilizando-se de um conhecimento científico para aplicar a técnica e modificar, melhorar, aprimorar os produtos oriundos do processo de interação deste com a natureza e com os demais seres humanos. 


\section{autêntica}

Dessa forma, entender o que é tecnologia passa também por entender "que inovação não significa apenas ter à disposição coisas como automóveis de luxo, televisores de altíssima definição ou netbooks" (MEDEIROS; MEDEIROS, 2010, p. 103). Na educação, sentimos, ainda, que falta muito para entender que a simples disponibilização do recurso - televisão, computador, smartphone, tablet - não garante uma inovação no processo de ensino- aprendizagem, se não for acompanhada de um bom planejamento de formação dos professores para seu uso. Portanto, consideramos tecnologia educacional a aplicação de recursos tecnológicos diversos no processo de ensino-aprendizagem.

Nas últimas décadas, pesquisas vêm demonstrando que o processo de integração das tecnologias no contexto educacional é complexo (VOSGERAU; PASINATO, 2013) e que a integração curricular ainda é um desafio a ser transposto (ALMEIDA; VALENTE, 2011). Ademais, o Projeto Político-Pedagógico (PPP) das escolas ainda não prevê diretrizes que possam nortear o processo de formação, a fim de auxiliar os professores no uso de tecnologias na educação (ROSSARI, 2012), apesar dos investimentos feitos em equipamentos. Na verdade, em uma sociedade digital, o maior investimento deveria ser na conexão de qualidade para todos, com baixos preços e disponível em todas as escolas.

Observa-se, então, que as discussões sobre a inserção das tecnologias na educação básica, no Brasil, já focalizaram diferentes objetos, como é demonstrado no levantamento produzido por Barreto (2006).

A utilização do vídeo como recurso pedagógico destaca-se nas discussões entre pesquisadores (MORAN, 1995; PFROMM NETTO, 1998) em meados da década de 1990:

Finalmente o vídeo está chegando à sala de aula. E dele se esperam, como em tecnologias anteriores, soluções imediatas para os problemas crônicos do ensino-aprendizagem. O vídeo ajuda a um bom professor, atrai os alunos, mas não modifica substancialmente a relação pedagógica (MORAN, 1995, p. 27).

Enquanto na escola os professores tentavam se adaptar aos vídeos e a essa tecnologia, políticas governamentais começavam a ser instauradas, definindo alternativas para a aquisição de outra nova tecnologia para as escolas públicas de educação básica brasileiras: o computador. Iniciou-se, então, uma nova discussão: computadores são úteis ou não para a educação? Esse tipo de investimento é válido ou não para melhorar a qualidade da educação do país? Os computadores favorecem ou não a aprendizagem? (VALENTE, 1993).

Mesmo sem respostas a tantas perguntas, no início da primeira década do século $X X I$, os computadores adentraram o espaço escolar e os professores passaram a ser protagonistas de uma esperada revolução pedagógica, ocasionada pela chegada desses equipamentos, a qual acabou por não acontecer da forma como se esperava. O olhar das pesquisas voltou-se, então, para o professor, emergindo as discussões sobre a lacuna tecnológica em sua formação inicial (VOSGERAU, 1999), o que estimulou a oferta de programas de capacitação, visando à sua familiaridade com os considerados novos recursos tecnológicos.

Nesse período, a preocupação com os fatores individuais, que poderiam influenciar a apropriação das tecnologias, como diferenças de gênero, experiência e nível de apropriação tecnológica e percepção sobre a tecnologia, considerados variáveis de nível micro (TONDEUR et al., 2008), desviaram o foco da culpabilidade da não integração, pela ausência de políticas públicas - nível macro - que garantissem a implementação e manutenção de um processo de uso das tecnologias nas escolas, como nos demonstram pesquisas predominantes no final do século XX, tanto no contexto internacional (TANG; ANG, 2002) quanto no nacional (BARRETO, 2006; ZUFFO, 2011). 


\section{autêntica}

Por sua vez, pesquisas sobre a utilização das tecnologias no contexto escolar destacavam as dificuldades existentes na apropriação das TICs na prática pedagógica do professor (VOSGERAU, 2005) e buscavam alternativas que pudessem auxiliar o processo de formação dos professores, para que essa apropriação ocorresse. Estabeleceram-se, assim, parcerias entre redes de ensino público e universidades para a formação técnico-pedagógica e consequente apropriação das tecnologias pelos professores (ALONSO; ALMEIDA, 2004; VOSGERAU, 2005). À época, destacava-se a importância da passagem do uso das tecnologias em sala de aula para sua integração curricular (ALMEIDA; VALENTE, 2011). A tecnologia precisaria estar integrada harmonicamente ao currículo, às práticas escolares (ALMEIDA; VALENTE, 2011) e ao contexto escolar, considerando a complexidade desse sistema.

Dessa forma, observa-se que, se a escola é uma organização que tem o mandato de promover o ensino e a aprendizagem (ARGYRIS; SCHÖN, 1978), espera-se que busquem alternativas e se incorporem recursos para que seus objetivos possam ser atingidos. Contudo, mesmo as tecnologias sendo aclamadas como parceiras na promoção da aprendizagem, sua integração no espaço escolar, tanto da educação básica quanto da educação superior, não tem tido o resultado esperado, apesar do grande investimento do governo, no caso das escolas públicas, e de instituições particulares. Essa é uma realidade não só do Brasil, mas também de outros países, conforme demonstrado por Guichon (2012).

Consideramos o professor uma "figura estratégica na sociedade intensiva de conhecimento" e que, "[...] mais que outras profissões, esta precisa de reconstrução completa, dentro da máxima: ser profissional hoje é, em primeiro lugar, saber renovar, reconstruir, refazer a profissão" (DEMO, 2009, p. 11).

Contudo, não é mais o professor o principal responsável para que novas práticas sejam desenvolvidas a partir das tecnologias; diversos são os fatores que contribuem para essa situação. As novas formas de se comunicar, de se relacionar, de buscar e selecionar informações e fazer com que elas se transformem em conhecimento têm trazido mudanças radicais para a sociedade, as quais não se refletem apenas na sala de aula, na prática de ensino do professor e na aprendizagem do aluno, mas na escola como um todo. Dessa forma, o esforço e o desafio político inicial deveriam ser a discussão e empenho na conexão para todos. Concomitantemente, dever-se-iam planejar formações continuadas e incluir no currículo das licenciaturas a formação nos letramentos, entre eles, midiáticos, digitais, da informação e científico, de modo a se poderem desenvolver práticas e metodologias de uso das diferentes ferramentas disponíveis, da reflexão e da ação pedagógica na apropriação das tecnologias, de acordo com os objetivos dos professores em aula (CAMAS, 2012).

O desafio do uso das tecnologias na sala de aula - que marcaria o empoderamento de professores e desenvolvimento de sua autonomia (FREIRE, 2002) e dos alunos que vivenciam a sociedade digital - é praticar conceitos como colaboração e cooperação, que não se relacionam, em hipótese alguma, à ação de transmissão. Muitos são os pesquisadores que se enveredaram no caminho de compreensão desses conceitos (BELLONI, 2006; BELLONI; GOMES, 2008; PAPERT, 1994; VALENTE, 1999) e trouxeram-nos o entendimento conceitual para o uso das TICs em sala de aula.

Assumimos que cooperação requer interação e colaboração pelo quais se desenvolvem

relações de respeito mútuo e não hierárquico entre os envolvidos, uma postura de tolerância e convivência com as diferenças e um processo de negociação constante [...] a diferença fundamental entre os conceitos de colaboração e cooperação reside no fato de que para haver colaboração 


\section{autêntica}

o indivíduo deve interagir com o outro, existindo ajuda mútua e unilateral. Para existir cooperação deve haver interação, colaboração, mas também objetivos comuns, atividades e ações conjuntas e coordenadas (BELLONI; GOMES, 2008, p. 731).

Nesse sentido, o professor na cibercultura tem o desafio de não mais ser o guardião da cultura e do conhecimento, tampouco um mero instrumento de transmissão. Assim, o desafio é formarmos professores que rompam o velho paradigma da educação bancária (FREIRE, 2002).

No Brasil, a política de formação dos professores, para os desafios que surgem com a sociedade permeada por tecnologias, tem sido centrada nas iniciativas que objetivam "o investimento em instrumentos, em cursos aligeirados e não nos processos, pautadas em decisões da administração de ensino desconsiderando as necessidades reais dos professores" (SIMONIAN, 2009, p. 56). Em grande parte dos cursos, ainda perdura a proposta de capacitar, partindo da ideia de que "o professor é descapacitado ou incapaz, e um curso propiciará a aquisição, pelo docente, de determinada capacidade" (BOENO, 2013, p. 38).

Nesses cursos, não se pensa em formar o professor para que ele assuma o papel reflexivo e de empoderamento do uso das tecnologias, de forma metodológica, com a finalidade de trazer inovações para suas aulas, deixando de ser um mero espectador e usuário acrítico de tecnologias, para refletir sobre sua ação, realizando um diálogo com a situação concreta de utilizar as TICs, na descoberta de novos modos de ser e de agir.

Concordamos com Oliveira e Mendes Sobrinho (2010), quando afirmam que o docente que reflete acerca de sua própria prática reconstrói competências pessoais e profissionais, redescobrindo uma nova forma de atuar. Acrescentaríamos que poderá ele também ser produtor de novos produtos educacionais gerados pela tecnologia. Entendemos, portanto, que o uso de tecnologias na educação é um grande aliado, não somente na formação de professores, mas também como um importante recurso didático-pedagógico, que deve ser considerado com suas metodologias, seja na aplicação e produção de materiais/conteúdos didáticos, seja na educação a distância, seja na educação presencial.

Dessa forma, em tempos de reformulação de políticas educacionais, faz-se necessário compreender como o PNE prevê espaço para as mudanças propostas/impostas em uma sociedade envolta pela cultura digital.

\section{O PROCESSO DA ANÁLISE DO CONTEÚDO}

Para a análise da Lei n 13.005, de 25 de junho de 2014, que institucionaliza o PNE, tivemos como premissa o desenvolvimento de uma cultura digital que considera a integração cotidiana das tecnologias digitais, com fins de melhoria da qualidade de vida, de aperfeiçoamento da democratização, de acesso às informações, de formação do cidadão para o mundo e de preparo do professor para a condução de uma formação que oportunize a concretização dessas finalidades.

O procedimento de análise iniciou-se pela inserção da conversão do documento disponível no site do Palácio do Planalto - Presidência da República para '.doc', perfazendo um total de 30 páginas, inseridas no software para análise de dados qualitativos Atlas. Ti. Foi utilizado o processo de codificação aberta (GIBBS, 2009), no qual o pesquisador lê o texto, frase por frase, e elabora questões a partir dos extratos selecionados, criando anotações, denominadas pelo software como memos, que permitem buscar as questões teóricas implícitas e incidências nos conjuntos dos extratos selecionados. Nessa codificação aberta, foram selecionados todos os parágrafos nos quais havia alguma menção a palavras relacionadas a tecnologias digitais e à cultura digital, nesse primeiro momento, sem necessariamente considerar o âmbito educacional, resultando na seleção de 37 extratos. 
Considerando que o documento analisado dividia-se em duas partes - a apresentação da lei e seus artigos e as metas e estratégias para o cumprimento da lei -, na primeira encontramos apenas três extratos (Figura 1). Como os aspectos trazidos pela lei tratavam a tecnologia como meio de divulgação (Figura 1 - [1:26]), um dos aspectos de desenvolvimento do cidadão (Figura 1 - [1:9]), e apenas uma citação sobre a tecnologia como recurso pedagógica de forma geral, centralizamos a análise na segunda parte do documento, que se referia às metas e às estratégias, contendo 34 extratos associados às tecnologias.

\section{FIGURA 1 - CITAÇÕES ASSOCIADAS A TECNOLOGIAS NA APRESENTAÇÃO DA LEI}

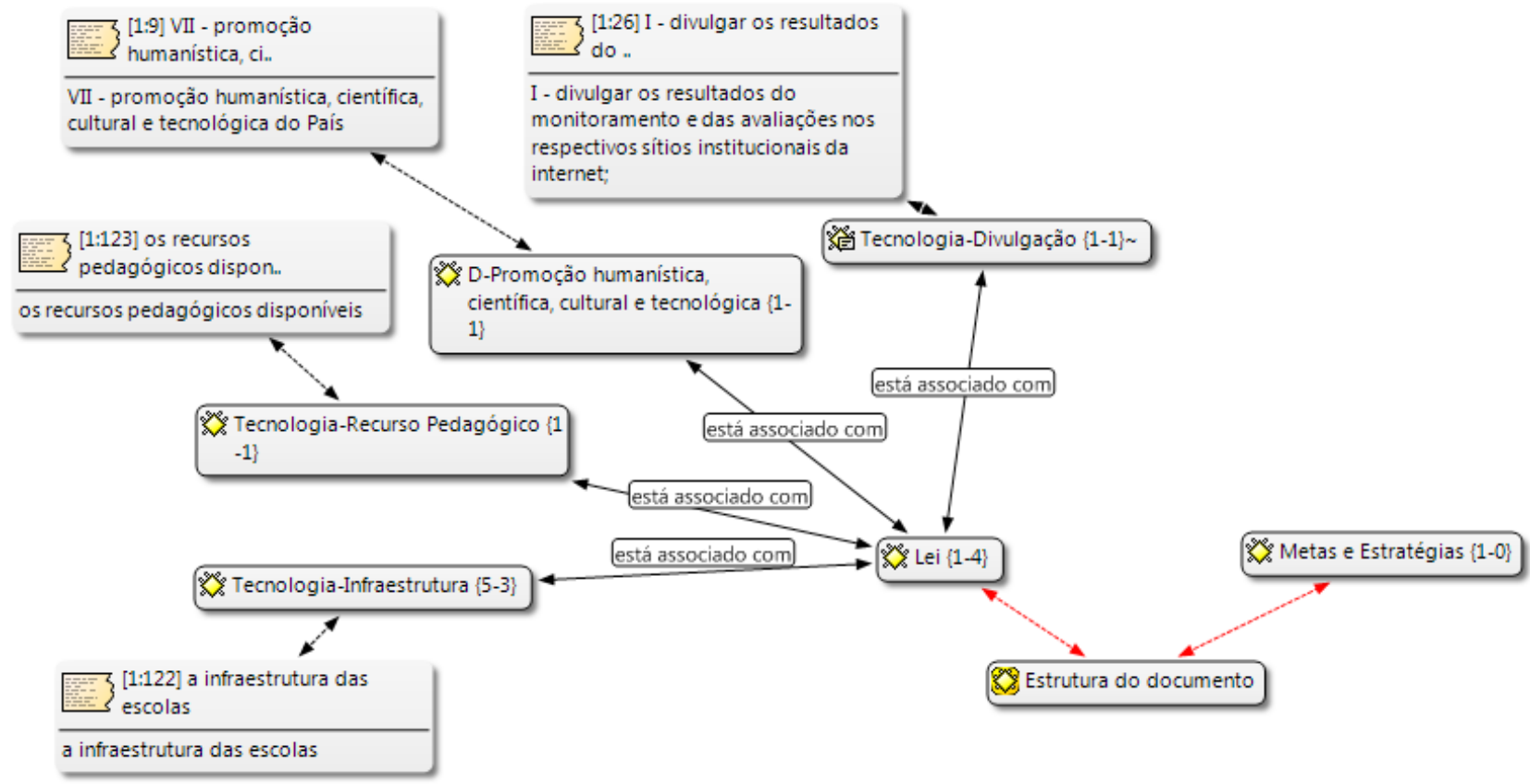

Na segunda etapa da análise, procedeu-se à categorização e à busca de sentido nos extratos selecionados, procurando-se respostas para as questões anotadas nos memos, como por exemplo, de que forma a tecnologia é mencionada?; quais aspectos de formação são previstos?; Como se dará a produção dos recursos mencionados?; Qual é o papel do professor nessa produção? Destaca-se, aqui, que a codificação aberta nos levou às questões mencionadas, a que buscamos responder nos resultados da análise apresentada a seguir.

\section{RESULTADOS E DISCUSSÃO}

Analisando as 19 metas do PNE, a partir do extrato dos textos, e considerando a palavra "tecnologia", encontramos 34 ocorrências, cuja categorização é apresentada na Tabela 1.

TABELA 1 - CATEGORIZAÇÃO DOS EXTRATOS SELECIONADOS EM METAS E ESTRATÉGIAS

\begin{tabular}{|c|c|}
\hline Ocorrência & Meta no PNE \\
\hline Tecnologia-Acervo Digital & 1 \\
Tecnologia-Disponibilização de Tecnologia Assistiva & 1 \\
Tecnologia-EaD & 3
\end{tabular}


Tecnologia-Formação

Tecnologia-Formação Continuada de Professores

Tecnologia-Inclusão Digital Idosos

Tecnologia-Infraestrutura

Tecnologia-Produção

Tecnologia-REA

Tecnologia-Relação entre Teoria e Prática

Tecnologia-Uso Educação Especial

Tecnologia Assistiva

Tecnologia como Dimensão

Tecnologias-Gestão

Tecnologias-Incentivo a parcerias para aquisição

Tecnologias-Salas Multifuncionais

Tecnologias Pedagógicas

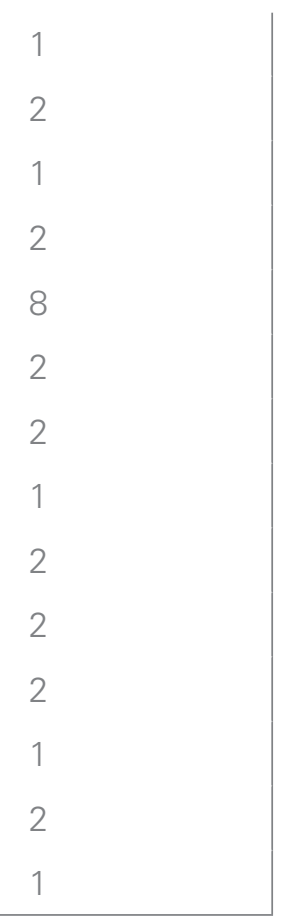

A partir do encontro da expressão 'tecnologia', disposta em diferentes dimensões, entendimentos e modalidades da educação, fizemos a busca pelas expressões "formação" e "formação continuada dos professores", que aparecem em três metas (Figura 2).

Na meta 1 (Figura 2 - [1:68]), a referência é apenas aos cursos de formação, pois se considera que deverá haver a articulação entre pós-graduação, núcleos de pesquisa e cursos de formação para profissionais da educação, contudo não há uma especificação de como se daria essa articulação. Mesmo sabendo que vários fatores podem contribuir para a integração das tecnologias (CAMAS, 2012; VOSGERAU; PASINATO, 2013), entendemos ser necessário ver o professor como a figura estratégia que conduzirá o desenvolvimento e daí a importância de sua formação ao longo da vida (DEMO, 2009).

\section{FIGURA 2 - METAS QUE CONTÊM AS EXPRESSÕES FORMAÇÃO E FORMAÇÃO DE PROFESSORES}

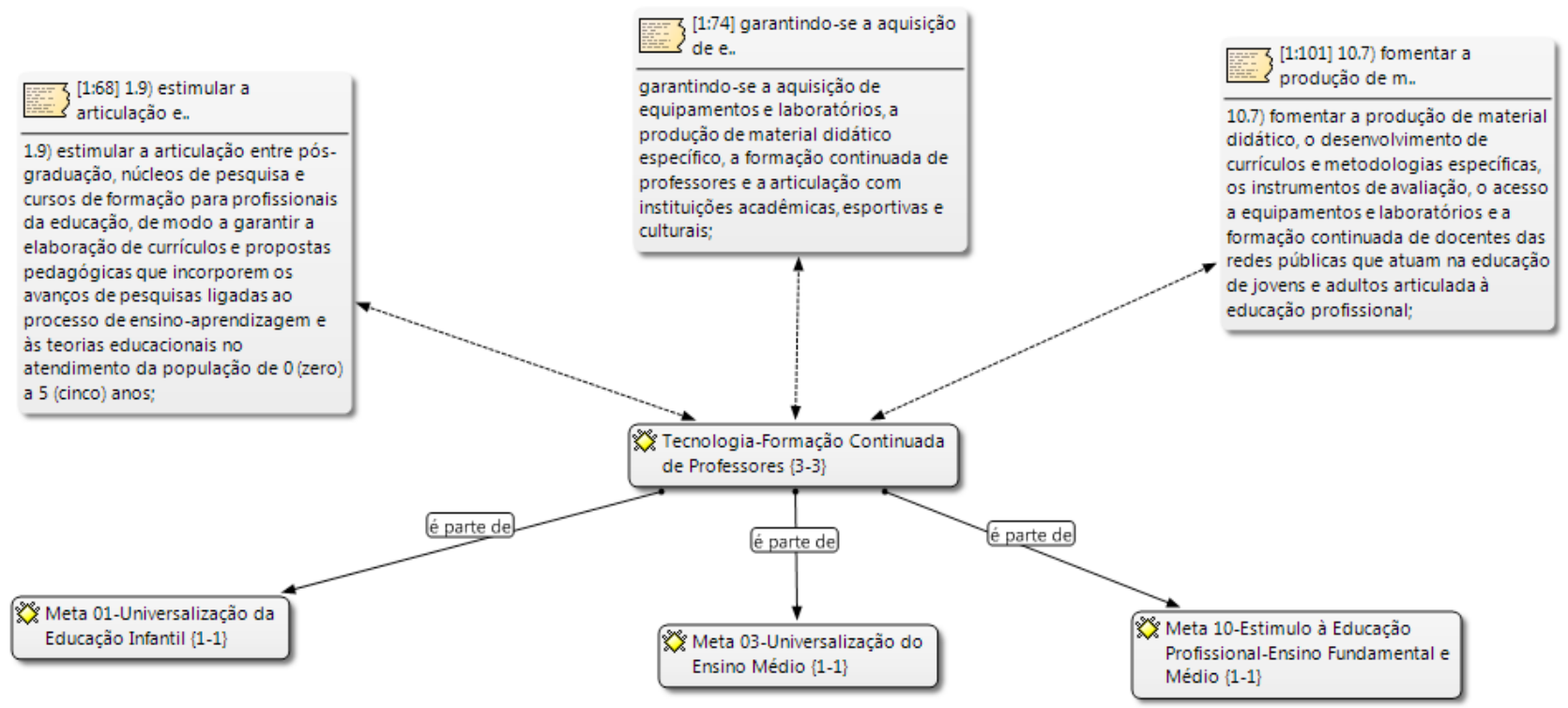

Fonte: Extratos do PNE (BRASIL, 2014) 


\section{DOCENTE}

autêntica

Nas metas 3 e 10 (Figura 2 - [1:74] e [1:101]), há referência à formação continuada de professores, que nos parece ser no sentido reduzido de que se deverá capacitar o professor a utilizar os equipamentos e os materiais didáticos que chegarão à escola. Reforça-se, aí, o sentido atribuído por Boeno (2013) de que o profissional é incapaz de criar, de conceber os instrumentos e os recursos necessários à sua prática pedagógica, restando-lhe apenas a função de utilizador.

Observamos, novamente, a questão de articulação com instituições acadêmicas, acrescentando-se aqui instituições esportivas e culturais. Entretanto, acreditamos que a formulação da meta 3 deve estar preocupada não mais com a aquisição simplista de equipamentos e laboratórios, mas, sim, na condição de todas as escolas terem acesso de qualidade à rede de computadores mundial: a internet. Ao discutirmos o PNE em plena sociedade digital, é inviável continuarmos a acreditar e a colocarmos como meta a ser alcançada apenas laboratório de informática, que, sabemos, pouco contribuirá para o desenvolvimento profissional do professor no sentido de fazê-lo dialogar com as infinitas possibilidades metodológicas das tecnologias em sala de aula.

Também surge a questão: garantir a quem a produção de material didático? À editora, como temos até hoje determinado? Ao professor, que não tem esse direito garantido? Ou aos dois? Se pensarmos na formação inicial e continuada do professor, garantindo seu desenvolvimento pleno e de qualidade, nada mais justo e possível numa sociedade preocupada com seu futuro. Poderíamos crer que a meta 3 seria um avanço, mas, sem a garantia da conexão à internet de qualidade para todos, pouca esperança ela nos dá.

Na continuidade de nossa análise, encontramos nas ocorrências levantadas, em oito metas, a expressão "produção de tecnologia", conforme ilustrado no Quadro 1.

QUADRO 1 - OCORRÊNCIAS DA EXPRESSÃO "PRODUÇÃO DE TECNOLOGIA"

\begin{tabular}{|l|l|}
\hline \multicolumn{1}{|c|}{ Meta } & \multicolumn{1}{c|}{ Ocorrência } \\
\hline $\begin{array}{l}\text { Fundamental }- \text { Universalização do Ensino } \\
\text { F- Universalização da }\end{array}$ & $\begin{array}{l}\text { 2.6) desenvolver tecnologias pedagógicas que combinem, de maneira articulada, } \\
\text { a organização do tempo e das atividades didáticas entre a escola e o ambiente } \\
\text { comunitário, considerando as especificidades da educação especial, das escolas do } \\
\text { campo e das comunidades indígenas e quilombolas; }\end{array}$ \\
\hline $\begin{array}{l}\text { Educação Especial } \\
\text { materiais didáticos, equipamentos e recursos de tecnologia assistiva, com } \\
\text { vistas à promoção do ensino e da aprendizagem, bem como das condições } \\
\text { de acessibilidade dos (as) estudantes com deficiência, transtornos globais do } \\
\text { desenvolvimento e altas habilidades ou superdotação; }\end{array}$ & $\begin{array}{l}\text { 5.4) fomentar o desenvolvimento de tecnologias educacionais e de práticas } \\
\text { pedagógicas inovadoras que assegurem a alfabetização e favoreçam a melhoria } \\
\text { do fluxo escolar e a aprendizagem dos (as) alunos (as), consideradas as diversas } \\
\text { abordagens metodológicas e sua efetividade; }\end{array}$ \\
\hline Alfabetização
\end{tabular}




\begin{tabular}{|c|c|}
\hline $\begin{array}{l}7 \text { - Qualidade na Educação } \\
\text { Básica }\end{array}$ & $\begin{array}{l}\text { 7.12) incentivar o desenvolvimento, selecionar, certificar e divulgar tecnologias } \\
\text { educacionais para a educação infantil, o ensino fundamental e o ensino médio e } \\
\text { incentivar práticas pedagógicas inovadoras que assegurem a melhoria do fluxo } \\
\text { escolar e a aprendizagem, assegurada a diversidade de métodos e propostas } \\
\text { pedagógicas, com preferência para softwares livres e recursos educacionais } \\
\text { abertos, bem como o acompanhamento dos resultados nos sistemas de ensino } \\
\text { em que forem aplicadas; }\end{array}$ \\
\hline $\begin{array}{l}9 \text { - Elevação da Taxa de } \\
\text { Alfabetização }\end{array}$ & $\begin{array}{l}\text { 9.11) implementar programas de capacitação tecnológica da população jovem e } \\
\text { adulta, direcionados para os segmentos com baixos níveis de escolarização formal } \\
\text { e para os (as) alunos (as) com deficiência, articulando os sistemas de ensino, a } \\
\text { Rede Federal de Educação Profissional, Científica e Tecnológica, as universidades, } \\
\text { as cooperativas e as associações, por meio de ações de extensão desenvolvidas } \\
\text { em centros vocacionais tecnológicos, com tecnologias assistivas que favoreçam a } \\
\text { efetiva inclusão social e produtiva dessa população; }\end{array}$ \\
\hline $\begin{array}{l}10 \text { - Estímulo à Educação } \\
\text { Profissional-Ensino } \\
\text { Fundamental e Médio }\end{array}$ & $\begin{array}{l}\text { 10.7) fomentar a produção de material didático, o desenvolvimento de currículos e } \\
\text { metodologias específicas, os instrumentos de avaliação, o acesso a equipamentos } \\
\text { e laboratórios e a formação continuada de docentes das redes públicas que atuam } \\
\text { na educação de jovens e adultos articulada à educação profissional; }\end{array}$ \\
\hline $\begin{array}{l}14 \text { - Elevação de Matrículas } \\
\text { Stricto Sensu }\end{array}$ & $\begin{array}{l}\text { 14.15) estimular a pesquisa aplicada, no âmbito das IES e das ICTs, de modo a } \\
\text { incrementar a inovação e a produção e registro de patentes. }\end{array}$ \\
\hline $\begin{array}{l}16 \text { - Formação na Pós- } \\
\text { Graduação Professores da } \\
\text { Educação Básica }\end{array}$ & $\begin{array}{l}\text { 16.4) ampliar e consolidar portal eletrônico para subsidiar a atuação dos professores } \\
\text { e das professoras da educação básica, disponibilizando gratuitamente materiais } \\
\text { didáticos e pedagógicos suplementares, inclusive aqueles com formato acessível; }\end{array}$ \\
\hline
\end{tabular}

Fonte: extratos do PNE (BRASIL, 2014)

Em todas as metas citadas, a questão da produção parece estar vinculada a um problema da educação a ser resolvido em cada um dos níveis da educação básica, mas, para que essas produções realmente possam acontecer, faz-se necessário que os problemas sejam levantados de forma clara, pois,

primeiro, identifica-se com clareza o problema a ser resolvido. Depois, definem-se os meios - conhecimentos científicos, técnicas, materiais e procedimentos gerenciais- capazes de conduzir ao resultado esperado, isto é, a produção de objetos, processos e serviços, novos ou aperfeiçoados que os especialistas chamam de inovações radicais e incrementais, respectivamente (MEDEIROS; MEDEIROS, 2010, p. 35).

Identificado o problema, para que se prossiga à próxima etapa - definição de meios -, é necessário que uma equipe se dedique à escolha dos conhecimentos científicos, das técnicas, dos materiais e dos procedimentos.

Os problemas reais poderão ser identificados pela pesquisa básica, que é citada nas metas 4 e 14. Na meta 4 - Universalização da Educação Especial -, por exemplo, a pesquisa apresenta-se como pré-requisito para que ocorram inovações incrementais, que "são aquelas ligadas às melhorias tecnológicas incorporadas ao 


\section{autêntica}

produto" (MEDEIROS; MEDEIROS, 2010, p. 36); nesse caso, o produto seria o ensino, a aprendizagem e a melhoria da educação dos alunos na educação especial: metodologias, materiais didáticos, tecnologias assistivas etc.

Fazem parte da produção para chegar a uma inovação incremental as metas 2 (faz referência a desenvolver tecnologias pedagógicas para a universalização do ensino fundamental), 5 (faz referência a fomentar o desenvolvimento de tecnologias educacionais para o uso na alfabetização), 7 (preocupa-se com a qualidade na educação básica e se refere ao incentivo para que se desenvolvam, selecionem, certifiquem e divulguem tecnologias educacionais), 9 (para que haja a elevação da taxa de alfabetização, orienta que aconteçam ações de extensões que favoreçam a efetiva inclusão social e produtiva da população jovem e adulta), 10 (destaca a produção de material para que aconteça o estímulo à educação profissional do ensino fundamental e médio) e 16 (refere-se a ampliar e consolidar portais eletrônicos para subsidiar a atuação dos professores).

Na meta 14 - Elevação de Matrículas Stricto Sensu -, aponta-se a pesquisa para desenvolver as inovações radicais, "que são aquelas que rompem com padrões antigos criando um produto totalmente novo e de grande impacto no mercado" (MEDEIROS; MEDEIROS, 2010, p. 36). Especifica-se que a inovação tem que ser incrementada e deverá haver registro de patentes, o que pressupõe uma trajetória complexa que conduz à inovação, a qual irá romper os padrões antigos da própria escola.

Observamos, por meio das relações estabelecidas entre os extratos referentes à formação e os extratos referentes à produção (Figura 3) na análise do trabalho, que, em nenhum momento, o professor é mencionado como sujeito da ação produtora. Essa omissão permite-nos identificar uma contradição acerca da importância da formação do professor para a produção do material didático. No único momento em que se expõe uma relação entre os dois códigos (Figura 3 - [1:101]), reforça-se a formação do professor como usuário de uma tecnologia pronta e não como um ator no processo que integra a tecnologia em sua prática para a construção e produção do conhecimento e de novas tecnologias. Dá-se a entender que ele será o usuário final dos produtos criados por outros, que muitas vezes não habitam o espaço escolar e, portanto, não reconhecem ou conhecem os problemas educacionais. 


\section{autêntica}

\section{FIGURA 3 - RELAÇÃo ENTRE FORMAÇÃO E PRODUÇÃo}

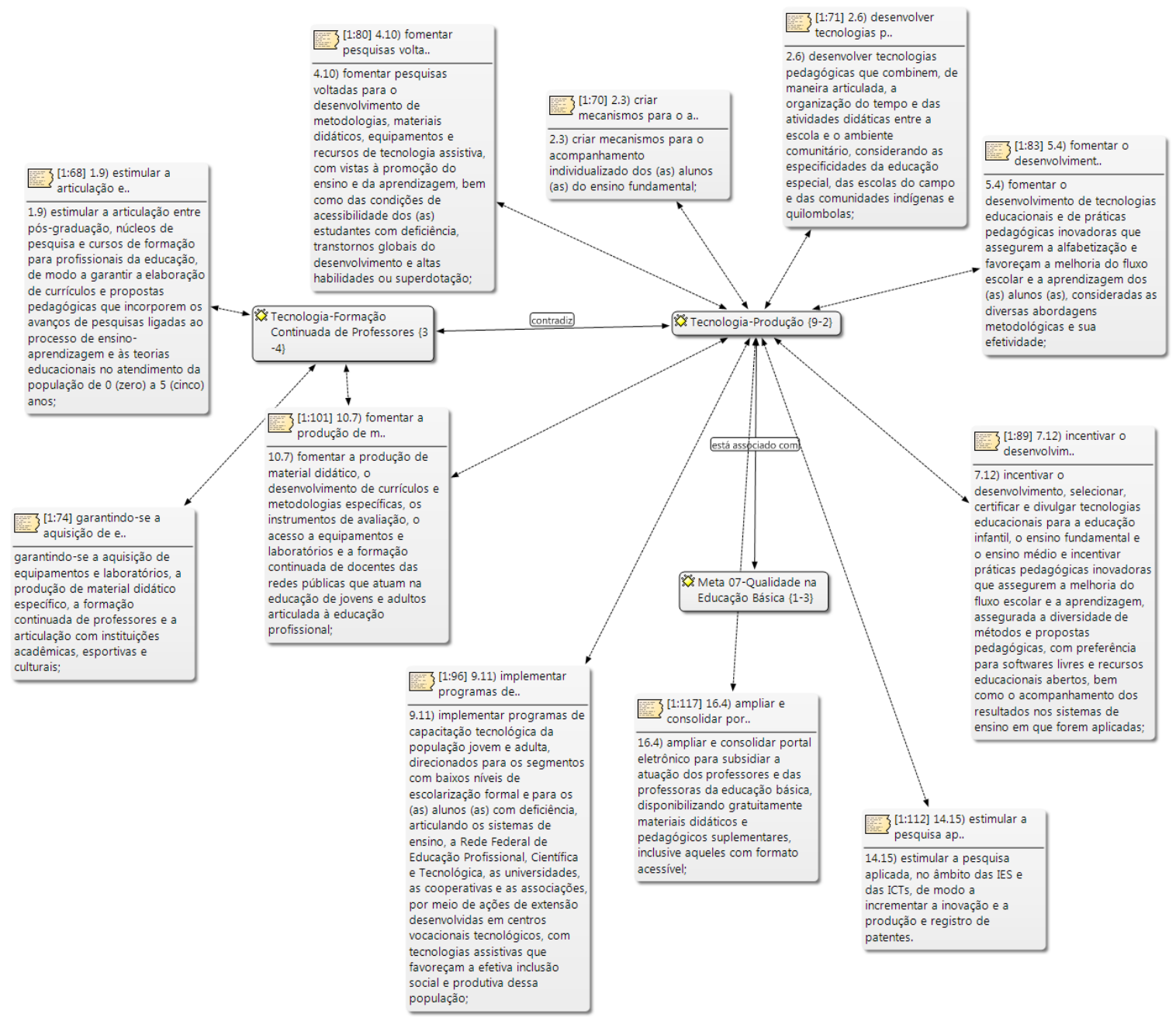

Fonte: extratos do PNE (BRASIL, 2014)

Sabemos, pelos diferentes projetos educacionais que incluem as TICs na escola, que implantar apenas a estrutura, com falhas técnicas, como, por exemplo, falta de conexão à rede, ou ofertar apenas a famosa capacitação técnica na ferramenta que se utilizará não mudará a educação, tampouco trará o que se solicita nas metas: a inovação. Da mesma forma, apenas capacitar massivamente professores que já estão sobrecarregados não fará com que se inclua no currículo escolar o uso de TICs - aqui, relembramos Barreto (2012), quando infere que, na educação, o 'mais pode ser menos'. Almeida e Valente (2011), nesse sentido, assinalam o avanço que significaria o professor refletir sobre o uso de uma ferramenta em sua aula e usá-la não por obrigação, mas porque entendeu seu uso no plano de aula.

Ressentimo-nos do fato de que nenhuma meta inclui, na formação dos futuros professores, as áreas temáticas de metodologias de uso de TICs na educação e de tecnologias como recursos didático-pedagógicos. Essa preocupação é fundamental para que tanto o futuro professor quanto aquele em exercício possam desenvolver-se e refletir sobre suas ações, como sujeitos da educação. Outro ponto que também nos preocupa é dissociação entre o uso de tecnologias e a educação híbrida (PFROMM NETTO, 1998), apesar de 


\section{autêntica}

as metas trazerem um avanço para nós, pesquisadores da área, ao citar 34 vezes a expressão tecnologias', sob diferentes perspectivas, como, por exemplo, o tratamento dos Recursos Educacionais Abertos (REAs), as tecnologias assistivas e as tecnologias em salas funcionais.

Por fim, cumpre alertar, aqui, que a produção de qualquer tecnologia para a educação deverá ser feita com a participação de equipes interdisciplinares que incluam o professor no processo de criação. Sem essa inclusão e sem criar uma equipe técnico-pedagógica, pouco se evoluirá tampouco se inovará.

\section{CONSIDERAÇÕES FINAIS}

Nosso estudo não pretende ser conclusivo, tampouco restritivo a outras interpretações. Tentamos encontrar, por meio de análise sistemática, as ocorrências no PNE das expressões anteriormente citadas. Desse modo, na comparação com documentos anteriores, entendemos que houve o avanço de trazer, como preocupação educacional, as tecnologias. Entretanto, não conseguimos localizar o que levaria ao real avanço na educação, que é a formação do professor para o uso significativo das tecnologias em sua aula.

Destarte, temos certeza de que devemos, como pesquisadores da área, não somente alertar, como fizemos aqui, mas também trabalhar para o avanço das seguintes discussões: o uso de tecnologias pelos professores nas escolas, a formação de professores para uso de tecnologias como recursos didáticos, de forma metodológica, e a implicação da produção de tecnologias para a educação.

Adotar, adaptar e apropriar as tecnologias na educação, em qualquer modalidade, é uma urgência, que deverá ser planejada por equipes interdisciplinares, pelo professor e pelo aluno, de modo a serem entendidas e usadas como metodologias de formação. Se não se entender esse ponto, não haverá documento que integre o recurso tecnológico à nação educacional. 


\section{REFERÊNCIAS}

ALMEIDA, M. E. B.; VALENTE, J. A. Tecnologias e currículo: trajetórias convergentes ou divergentes? São Paulo: Paulus, 2011.

ALONSO, M.; ALMEIDA, M. E. B. Inserção de tecnologias na escola e formação continuada e em serviço de gestores. São Paulo: PUCSP, 2004. Disponível em: <http://www.esdconsultoria.com.br/matapoio/biblioteca/ texto_pdf/texto14.pdf>. Acesso em: 20 abr. 2015.

ARGYRIS, C.; SCHÖN, D. Organizational learning: a theory of action perspective. Reading: Addison-Wesley, 1978.

BARRETO, R. G. (Coord.). Educação e tecnologia (1996-2002). Brasília, DF: MEC/INEP, 2006.

BARRETO, R. G. A recontextualização das tecnologias da informação e da comunicação na formação e no trabalho docente. Educação e Sociedade. Campinas, v. 33, n. 121, p. 985-1002, 2012.

BELLONI, M. L. Educação a distância. 4. ed. Campinas: Autores Associados, 2006.

BELLONI, M. L.; GOMES, N. G. Infância, mídias e aprendizagens: cenários de mudança. Educação e Sociedade. Campinas, v. 29, n. 104, p. 717-746, 2008.

BOENO, R. K. Formação continuada para o uso de tecnologias em sala de aula: o que os professores querem. Curitiba: UFPR. Dissertação de Mestrado - Programa de Pós Graduação em Educação. Curitiba, 2013.

BRASIL. Lei n. 13.005, de 25 de junho de 2014. Aprova o Plano Nacional de Educação - PNE e dá outras providências. Diário Oficial da União, Brasília, DF, 26 jun. 2014. Disponível em: <http://www.planalto.gov.br/ CCIVIL_03/_Ato2011-2014/2014/Lei/L13005.htm>. Acesso em: 5 abr. 2015.

BUENO, N. L. O desafio da formação do educador para o ensino fundamental no contexto da educação tecnológica. Curitiba: Centro Federal de Educação Tecnológica do Paraná. Dissertação de Mestrado - Programa de Pós Graduação em Educação. Curitiba, 1999.

CAMAS, N. P. V. A literacia da informação na formação de professores. TONUS, M.; CAMAS, N. P. V. (Org.). Tecendo fios na educação: da informação nas redes à construção do conhecimento mediada pelo professor. Curitiba: CRV, 2012.

CASTELLS, M. A sociedade em rede. Tradução de Roneide Venâncio Majer. São Paulo: Paz e Terra, 1999. (A era da informação: economia sociedade e cultura, v. 1).

DEMO, P. Professor do futuro e reconstrução do conhecimento. 6. ed. Petrópolis: Vozes, 2009.

FREIRE, P. Pedagogia da autonomia: saberes necessários à prática educativa. 25. ed. São Paulo: Paz eTerra, 2002.

GIBBS, G. Análise de dados qualitativos. Porto Alegre: Artmed, 2009.

GUICHON, N. Les usages des TIC par les lycéens - déconnexion entre usages personnels et usages scolaires. Conferénce donnée au Centre de recherche interuniversitaire sur la formation et la profession enseignante (CRIFPE). 2012. Disponível em: <http://www.crifpe.ca/conferences/view/166>. Acesso em: 20 abr. 2015. 


\section{autêntica}

LÈVY, P. O que é o virtual. São Paulo: 34, 1996.

LÈVY, P. Cibercultura. São Paulo: 34, 1999.

MEdeIROS, J. A.; MEDEIROS, L. A. O que é tecnologia. 2. ed. São Paulo: Brasiliense, 2010.

MORAN, J. M. O vídeo na sala de aula. Comunicação \& Educação. São Paulo, v. 2, p. 27-35, jan./abr. 1995.

Disponível em: <http://www.eca.usp.br/prof/moran/vidsal.htm>. Acesso em: 20 jan. 2015.

OLIVEIRA, C. M. B.; MENDES SOBRINHO, J. A. C. Os saberes docentes na educação a distância: reflexões teóricas sobre a prática pedagógica do professor autor. 2010. Disponível em: <http://www.ufpi.br/subsiteFiles/

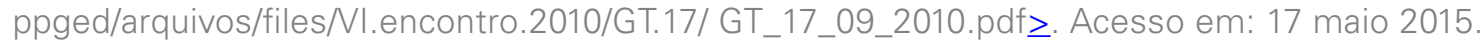

PAPERT, S. A máquina das crianças: repensando a escola na era da informática. Porto Alegre: Artes Médicas, 1994.

PFROMM NETTO, S. Telas que ensinam - mídia e aprendizagem: do cinema ao computador. Campinas: Alínea, 1998.

ROSSARI, M. A integração das tecnologias nos projetos políticos-pedagógicos: realidades e desafios. 2012. 215 f. Dissertação (Mestrado) - Pontifícia Universidade Católica do Paraná, Curitiba, 2012.

SIMONIAN, M. Formação continuada em ambiente virtual de aprendizagem: elementos reveladores da experiência de professores da educação básica. 2009. Dissertação (Mestrado) - Universidade Federal do Paraná, Curitiba, 2009.

TANG, P. S.; ANG, P. H. The diffusion of information technology in Singapure schools: a process framework. New Media \& Society, n. 4, p. 457-478, 2002.

TONDEUR, J. et al. Preparing pre-service teachers to integrate technology in education: a synthesis of qualitative evidence. Computers \& Education, n. 59, p. 134-144, 2012.

TÜRCKE, C. Sociedade excitada: filosofia da sensação. Tradução de Antônio Zuin, Fabio Durão, Francisco Fontanella e Mario Frungillo. Campinas: Edunicamp, 2010.

VALENTE, J. A. Computadores e conhecimento: repensando a educação. Por que o computador na educação? Campinas: Unicamp, 1993.

VALENTE, J. A. (Org.). O computador na sociedade do conhecimento. Campinas: UNICAMP/NIED, 1999.

VOSGERAU, D. S. A. R. A utilização de recursos tecnológicos na formação de professores. 1999. 124 f. Dissertação (Mestrado) - Pontifícia Universidade Católica do Paraná, Curitiba, 1999.

VOSGERAU, D. S. A. R. Reconception d'une formation à l'intégrationdes TIC à l'enseignementà partir de I'analyse d'une pratique, de sés fonctionnalités et de sés dysfonctions. 2005. Thèse (Grade de Philosophie Docteur) - Université de Montréal, Montréal, 2005. 
VOSGERAU, D. S. A. R.; PASINATO, N. M. B. Proposta de indicadores para avaliação dos estágios de integração das TIC no contexto escolar. ALMEIDA, M. E. B. A.; DIAS, P.; SILVA, B. D. (Org.). Cenários de inovação para a educação na sociedade digital. São Paulo: Loyola Jesuítas, 2013. p. 175-187.

ZUFFO, D. A formação de professores para o uso das tecnologias educacionais: o que apontam as teses e dissertações defendidas no Brasil no período de 2003 a 2008. 2011. 149 f. Dissertação (Mestrado) - Pontifícia Universidade Católica do Paraná, Curitiba, 2011. Disponível em: <http://www.biblioteca.pucpr.br/tede/tde_busca/arquivo. php?codArquivo=1890>. Acesso em: 5 mar. 2013. 
